\title{
Jennifer Saltzstein, The refrain and the Rise of the Vernacular in Medieval French Music and Poetry
}

\section{G. Matteo Roccati}

\section{(2) OpenEdition}

10 Journals

\section{Édition électronique}

URL : http://journals.openedition.org/studifrancesi/4294

DOI : 10.4000/studifrancesi.4294

ISSN : 2421-5856

Éditeur

Rosenberg \& Sellier

\section{Édition imprimée}

Date de publication : 1 septembre 2016

ISSN : 0039-2944

\section{Référence électronique}

G. Matteo Roccati, « Jennifer Saltzstein, The refrain and the Rise of the Vernacular in Medieval French Music and Poetry », Studi Francesi [En ligne], 179 (LX | II) | 2016, mis en ligne le, consulté le 18 septembre 2020. URL : http://journals.openedition.org/studifrancesi/4294 ; DOI : https://doi.org/ 10.4000/studifrancesi.4294

Ce document a été généré automatiquement le 18 septembre 2020.

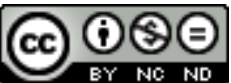

Studi Francesi è distribuita con Licenza Creative Commons Attribuzione - Non commerciale - Non opere derivate 4.0 Internazionale. 


\title{
Jennifer Saltzstein, The refrain and the Rise of the Vernacular in Medieval French Music and Poetry
}

\author{
G. Matteo Roccati
}

\section{RÉFÉRENCE}

JENNIFER SALTZSTEIN, The refrain and the Rise of the Vernacular in Medieval French Music and Poetry, Cambridge, D. S. Brewer, 2013, «Gallica» 30, XII-196 pp.

1 Selon la thèse centrale de ce livre, la citation de refrains, loin de constituer un témoignage de la diffusion orale des chansons d'où ils seraient tirés, notamment des rondets de carole - théorie communément admise depuis Jeanroy bien qu'avec des fortes révisions - doit être mise en rapport avec la pratique savante du commentaire: les refrains - qui ont pu circuler comme «written artifacts» (p. 13) - fonctionnent en fait comme des autorités. Les différents chapitres - où la dimension musicale est prise en compte au même titre que la dimension littéraire-développent cette thèse en l'intégrant dans un discours beaucoup plus large sur l'essor du vulgaire en tant que langue de culture.

Dans le premier chapitre, après avoir parcouru les théories proposées dans le passé, l'A. souligne la multiplicité des formes de circulation des refrains, formes qui souvent ne portent pas les traces habituelles d'une transmission orale. Le deuxième examine une série de refrains apparaissant dans deux textes issus de la culture cléricale - une traduction d'Ovide, un recueil monastique de proverbes - et note la parenté entre ces citations et la pratique exégétique. Le chapitre III examine un corpus de refrains qu'on peut rattacher au milieu des trouvères arrageois pour mettre en évidence une sorte de «local poetic canon of vernacular auctoritates» (p.7), affirmation du prestige de la tradition musicale de la ville. Un tel contexte permet de mieux comprendre les citations de refrains mises en œuvre par Adam de la Halle, sa posture de maitre et la 
reconnaissance dont il a joui de son vivant et après sa mort (ch. IV). Le dernier chapitre (V) est consacré à l'héritage de ces pratiques au XIve siècle à travers l'examen, à titre d'exemple, d'un refrain du xiII ${ }^{\mathrm{e}}$ siècle repris dans l'œuvre de Guillaume de Machaut (Puis qu'il vous plaist, forment m'agrée). Bibliographie (pp. 169-188) et index complètent le volume. 